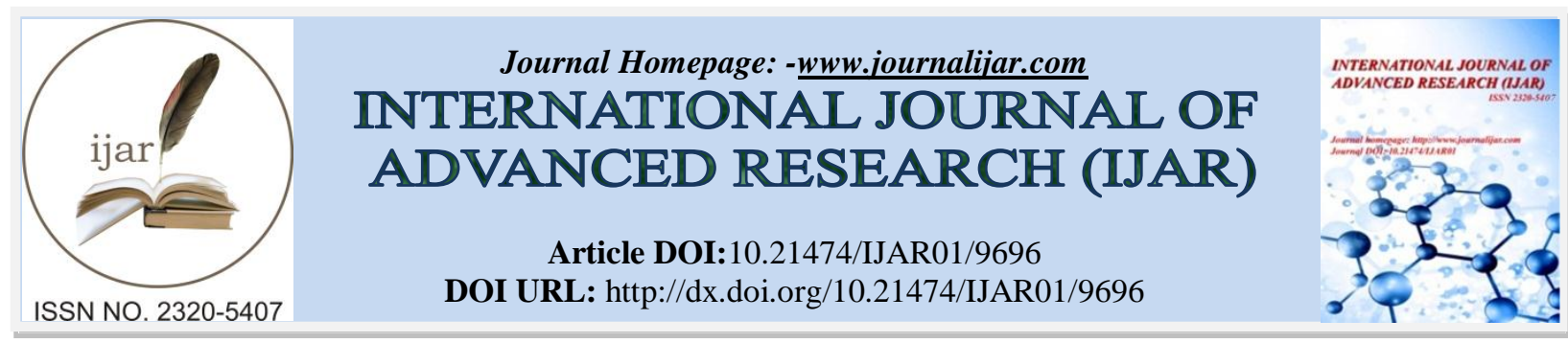

RESEARCH ARTICLE

\title{
RECRUITMENT OF ALVARADO AND MODIFIED RIPASA SCORES IN DIAGNOSIS OF ACUTE APPENDICITIS.
}

\author{
Mohamed I Farid ${ }^{1}$, Rasha S Elsayed ${ }^{1}$, Alaaedin Ramadan ${ }^{1}$ and Hazem Nour ${ }^{1}$ \\ General surgery department zagazig university Egypt
}

\section{Manuscript Info}

Manuscript History

Received: 08 July 2019

Final Accepted: 10 August 2019

Published: September 2019

Key words:-

ALVARADO, RIPASA, acute appendecitis

\section{Abstract}

Background: Diagnosis of acute appendicitis depends mainly on the surgeon's skills, as there is no single test that can confirm or rule out diagnosis, most of cases are first met by young surgeons in the emergency departments, so a diagnostic score which is easy applicable with good diagnostic accuracy was needed, ALVARADO and modified RIPASA scores are known but none of them proved to be better than the other.

Patients and method: ALVARADO and modified RIPASA scores were applied simultaneously on 224 patients with right lower quadrant pain, results of the scores were compared to the results of histopathological examination of the appendectomy specimen.

Results: ALVARADO score has positive predictive value (PPV) $100 \%$, negative predictive value $36.5 \%$, (NPV), sensitivity $66.3 \%$, specificity $100 \%$, and diagnostic accuracy $71.8 \%$. Modified RIPASA score has positive predictive value (PPV) $90.4 \%$, negative predictive value (NPV) $92.3 \%$, sensitivity $98.9 \%$, specificity $55.8 \%$, and diagnostic accuracy $90.6 \%$.

Conclusion: ALVARADO score is more specific, but modified RIPASA score is more sensitive, in diagnosis of acute appendicitis, if both scores were applied together to all patients presented with acute right lower quadrant pain a better accuracy could be obtained, that can decreases negative appendectomy rate.

Copy Right, IJAR, 2019,. All rights reserved.

\section{Introduction:-}

Acute appendicitis is a common surgical emergency, it accounts for 15-20\% of acute abdominal pain.[1, 2]. Appendectomy found to be the most common emergency operation performed by general surgeons as it doesn't require wide experience and for fear of complications of unresolved appendicitis. [3, 4].

Diagnosis of appendicitis depends largely on the clinical experience of the practicing surgeon, till now no laboratory test that can hundred percent exclude or confirm diagnosis of acute appendicitis, ultrasound has sensitivity about $85 \%$ and specificity about $90 \%$ for the diagnosis of acute appendicitis. [5].

Computerized tomography (CT) was implicated in diagnosis of suspected appendicitis with high specificity and sensitivity; it helps decreasing the rate of negative appendectomy and reduced the number of complicated cases due 
to neglected treatment. But CT is not in the hands of every surgeon especially in the developing and poor countries. [6].

Negative appendectomy rate ranged between $10-15 \%$, may be greater in some high-risk populations. Consideration of negative appendectomy or not depend on histopathological examination. Negative appendectomy not only costs the health service authorities a high percentage of the healthcare budget, but it also exposes the patients to the hazards of unnecessary surgery $[7,8]$.

With the aim of a better clinical prediction of acute appendicitis, and as trials of decreasing negative appendectomy rate several diagnostic scores was emerged. [9, 10].

The Criteria of the scoring system for reducing the negative appendectomy rate is clinically based, non-invasive, requires no special equipment and has been used successfully by house surgeons and junior registrars [11].

Alvarado scoring system is one of the most commonly used scoring tool which incorporates symptoms, signs and laboratory investigations to reach the diagnosis. RIPASA scoring system was claimed to have better outcomes in Asian populations, we don't have much studies to test the reliability of RIPASA or ALVARADO scoring systems in the Egyptian population.

\section{Patient and Methods}

This study is a cross sectional observational study which was conducted in Zagazig University Hospitals in the emergency unit, over a period of 12 months from august 2018 to August 2019. Over 224 patients presented with right lower quadrant pain.

All patients were informed and consented; the study was approved by the institutional research board and ethical committee of Zagazig University.

All patients underwent a thorough history taking, clinical examination, lab tests in the form of CBC and urine analysis of selected patient, and ultrasound examination of the abdomen and pelvis,

ALVARADO and RIPASA scoring systems were applied simultaneously for all patients away from the practicing surgical team. Decision for surgery or not was taken by the attending surgeon, surgery performed as usual and postoperative histopathological examination of the appendix specimen was done.

Demographic data of patients, preoperative diagnostic criteria, data of ALVARADO and RIPASA scoring systems, and result of histopathology were collected and analyzed using the proper statistical tests.

Inclusion criteria:

Patients suspected acute appendicitis in emergency department. Age above 14 years old.

Exclusion criteria:

Patients with right loin pain referred to groin as renal pain, history of urolithiasis, history of pelvic inflammatory disease, pregnant females, patients with generalized peritonitis, complicated appendicitis (appendicular mass, appendicular abscess), diabetic and Immunocompromized patients, neurological deficits interfere with the ability to localize abdominal pain.

The patients who were treated conservatively in hospital then discharged home were contacted and followed up. And those who relieved within one week on medical treatment were considered negative cases.

Alvarado Scoring System:

\begin{tabular}{|l|l|}
\hline Mnemonic (MANTRELS) & Value \\
\hline Symptom & 1 \\
\hline Migration of pain to Right iliac fossa. & 1 \\
\hline Anorexia & 1 \\
\hline Nausea-vomiting & 2 \\
\hline Signs & 2 \\
\hline Tenderness in right lower quadrant.
\end{tabular}




\begin{tabular}{|l|l|}
\hline Rebound pain & 1 \\
\hline Elevation of temperature $>37.3^{\circ} \mathrm{C}$ & 1 \\
\hline Laboratory & 2 \\
\hline Leukocytosis & 1 \\
\hline Shift to the left (neutrophilia) & 10 \\
\hline Total score & 10 \\
\hline
\end{tabular}

Interpretation of ALVRADO score

- $\quad 5$ not appendicitis

- 5-6 likely appendicitis

- 7 - 10 most likely appendicitis

Modified RIPASA scoring system:

\begin{tabular}{|c|c|c|}
\hline & & score \\
\hline \multicolumn{3}{|l|}{ 1.Patient. } \\
\hline & Female & 0.5 \\
\hline & Male & 1.0 \\
\hline & Age $\leq 39.9$ years & 1.0 \\
\hline & Age $\geq 40$ years & 0.5 \\
\hline \multicolumn{3}{|l|}{ 2.symptoms } \\
\hline & RIF pain & 0.5 \\
\hline & Pain migration to RIF & 0.5 \\
\hline & Anorexia & 1.0 \\
\hline & Nausea \& Vomiting & 1.0 \\
\hline & Duration of symptoms $\leq 48 \mathrm{hrs}$ & 1.0 \\
\hline & Duration of symptoms $\geq 48 \mathrm{hrs}$ & 0.5 \\
\hline \multicolumn{3}{|l|}{ 3.signs } \\
\hline & RIF tenderness & 1.0 \\
\hline & Guarding & 2.0 \\
\hline & Rebound tenderness & 1.0 \\
\hline & Rovsing's sign & 2.0 \\
\hline & Fever $\geq 37^{\circ} \mathrm{C} \leq 39^{\circ} \mathrm{C}$ & 1.0 \\
\hline \multicolumn{3}{|l|}{ 4.Investigation } \\
\hline & Raised WBC & 1.0 \\
\hline & Negative urine analysis & 1.0 \\
\hline & Total score & 16.5 \\
\hline
\end{tabular}

Interpretation of modified RIPASA score

- $<5$ Probability of acute appendicitis is unlikely.

- 5-7.0 Low probability of acute appendicitis.

- 7.5-11.0 Probability of acute appendicitis is high.

- > 12 Definite acute appendicitis.

\section{Results:-}

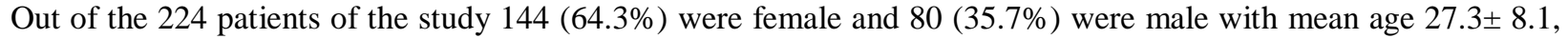
the most frequent complaint was pain shift to right iliac fossa followed by fever the least complain was anorexia and the most frequent clinical sign was tender Mc Burney's point followed by rebound tenderness and positive Rovsing's sign. Demographic criteria and the presenting manifestations presented in table 1. 
Table (1) demographic criteria and presenting manifestations.

\begin{tabular}{|l|l|l|l|}
\hline \multicolumn{2}{|l|}{} & Number & Percentage \\
\hline gender & Male & 80 & $35.7 \%$ \\
\cline { 2 - 4 } & Female & 144 & $64.3 \%$ \\
\hline Age & $27.3 \pm 8.1$ & $100 \%$ \\
\hline RIF pain & 56 & $100 \%$ \\
\hline Pain migration to RIF & 56 & $53.6 \%$ \\
\hline Fever & 30 & $44.6 \%$ \\
\hline Anorexia & 25 & $46.4 \%$ \\
\hline Nausea \& vomiting & 26 & $100 \%$ \\
\hline RIF tenderness & 56 & $32.1 \%$ \\
\hline Guarding & 18 & $89.3 \%$ \\
\hline Rebound tenderness & 50 & $71.4 \%$ \\
\hline Rovsing's sign & 40 & \\
\hline
\end{tabular}

Out of the 224 patients, 216 underwent appendectomy and 8 patients relieved with conservative measures, histopathological examination of the operated cases confirmed diagnosis of appendicitis in 181 cases, and revealed negative results in 35 cases (negative appendectomy rate 16.2\%. total number of proved non appendicitis was 43 cases.(operated and non-operated).

ALVARADO score diagnosed appendicitis in 120 patients all of them confirmed by histopathological examination, (true positive), It ruled out appendicitis in 104 cases, 61 of them were positive after histopathological examination. As shown in table 2.

In comparison to histopathological results ALVARADO score has positive predictive value (PPV) $100 \%$, negative predictive value $36.5 \%$, (NPV), sensitivity $66.3 \%$, specificity $100 \%$, and diagnostic accuracy $71.8 \%$.

Table 2 ALVARADO score findings.

\begin{tabular}{|l|l|l|l|}
\hline Alvarado score & Total no of patients & No appendicitis & appendicitis \\
\hline$<7$ & 104 & 35 & 61 \\
\hline$\geq 7$ & 120 & 0 & 120 \\
\hline total & 224 & 35 & 181 \\
\hline
\end{tabular}

Modified RIPASA score diagnosed appendicitis in 198 patients 179 of them confirmed by histopathological examination (true positive) and 19 cases were negative (false positive), modified RIPASA score also ruled out appendicitis in 26, two of them were positive ( false negative) after histopathological examination as shown in table 3. In comparison to histopathological results modified RIPASA score has positive predictive value (PPV) $90.4 \%$, negative predictive value (NPV) $92.3 \%$, sensitivity $98.9 \%$, specificity $55.8 \%$, and diagnostic accuracy $90.6 \%$.

Table 3 modified RIPAS score findings

\begin{tabular}{|l|l|l|l|}
\hline Modified RIPASA score & Total no of patients & No appendicitis & appendicitis \\
\hline$<7.5$ & 26 & 24 & 2 \\
\hline$\geq 7.5$ & 198 & 19 & 179 \\
\hline total & 224 & 35 & 181 \\
\hline
\end{tabular}

Diagnostic criteria of ALVARADO and modified RIPASA scores are presented in table 4, throughout these findings ALVARADO score is superior in diagnosing acute appendicitis without negative appendectomy rate while modified RIPASA score is superior in excluding acute appendicitis and overall diagnostic accuracy.

Table 4 diagnostic criteria of ALVARADO and modified RIPASA scores

\begin{tabular}{|l|l|l|l|l|l|l|}
\hline & sensitivity & specificity & PPV & NPV & Accuracy & $\begin{array}{l}\text { Negative } \\
\text { appendectomy }\end{array}$ \\
\hline ALVARADO & $66.3 \%$ & $100 \%$ & $100 \%$ & $36.5 \%$ & $71.8 \%$ & $0 \%$ \\
\hline $\begin{array}{l}\text { Modified } \\
\text { RIPASA }\end{array}$ & $98.9 \%$ & $55.8 \%$ & 90.4 & $92.3 \%$ & $90.6 \%$ & $9.6 \%$ \\
\hline
\end{tabular}




\section{Discussion:-}

Up to date there was no single investigation that exclusively confirms or rule out the diagnosis of acute appendicitis. CT has a high level of sensitivity and specificity in diagnosis of acute appendicitis, but unfortunately it can't be available in every place or for every patient especially in areas with limited resources, thus many clinical and laboratory scores emerged aiming at decreasing the rate of negative appendectomy.

In the present study we found that female to male ratio is 1.8 to 1 that is different from some studies this difference had no impact on the results of the study, the mean age was $27.3 \pm 8.1$ years, most patients were in their $3^{\text {rd }}$ decade as we excluded patients of pediatric age.

In the present study the most common symptoms was right iliac pain, fever and pain shift, with nausea being the least presenting symptom. Tender Mc Burney's point is the commonest sign these findings coincides with most of the studies.

Regarding ALVARADO score, it has positive predictive value (PPV) 100\%, negative predictive value 36.5\%, (NPV), sensitivity $66.3 \%$, specificity $100 \%$, and diagnostic accuracy $71.8 \%$.other studies has a varying results, the study of Konan [11], has similar results but studies of Verma [12], and Chong [13],reported a better accuracy.

MODIFIED RIPASA score has positive predictive value (PPV) $90.4 \%$, negative predictive value (NPV) $92.3 \%$, sensitivity $98.9 \%$, specificity $55.8 \%$, and diagnostic accuracy $90.6 \%$. These findings are similar to the results of Chong [13] and Alanjadat [14], and higher than in the studies of Erdem [15].

Negative appendectomy rate of this study is $16.2 \%$ which is higher than the study of Verma [12] and similar to the study of Alanjadat [14].

\section{Conclusion:-}

ALVARADO score is more specific for diagnosis of acute appendicitis but modified RIPASA score is more sensitive for exclusion of acute appendicitis; if both scores were applied together to all patients presented with acute right lower quadrant pain we will get better accuracy that can decreases negative appendectomy rate.

\section{References:-}

1. N N, Mohammed A, Shanbhag V, Ashfaque K, S A P A Comparative Study of RIPASA Score and ALVARADO Score in the Diagnosis of Acute Appendicitis. J Clin Diagn Res JCDR. 2014;8(11).

2. Nema P, Jain AK. A clinical comparative study of different scoring systems in acute appendicitis. Int Surg J 2016; 3(1): 184-188.

3. Blitman N.M., Anwar M., Brady K.B., Taragin B.H., Freeman K. Value of focused appendicitis ultrasound and Alvarado score in predicting appendicitis in children: can we reduce the use of CT? Am J Roentgenol. 2015;204(6):W707-W712.

4. N. Bakti, A. Hussain, S. El-Hasani A rare complication of acute appendicitis: superior mesenteric vein thrombosis Int. J. Surg. Case Rep., 25 (2011), pp. 0-252.

5. Denizbasi A, Unluer EE: The role of the emergency medicine resident using the Alvarado score in the diagnosis of acute appendicitis compared with the general surgery resident. Eur J Emerg Med. 2003, 10: 296-301.

6. Lin KB, Lai KR, Yang NP, Chan CL, Liu YH, Pan RH, Huang CH. Epidemiology and socioeconomic features of appendicitis in Taiwan: a 12-year population-based study. World J Emerg Surg. 2015;10:42.

7. 7-Guller U, Rosella L, McCall J, Brugger LE, Candinas D. Negative appendicectomy and perforation rates in patients undergoing laparoscopic surgery for suspected appendicitis. Br J Surg 98:589-95.

8. McGory ML, Zingmond DS , Nanayakkara D , Maggard MA, Ko CY . Negative appendectomy rate: infl uence of CT scans. Am Surg 2005 ; 71 ( 10 ): 803 - 808 .

9. Sania Sabir, Shahroz Saud Ahmed, Maria Zafar. Evaluation of RIPASA and ALVARADO Score for Diagnosis of Acute Appendicitis. Journal of Rawalpindi Medical College (JRMC); 2018;22(1): 43-46

10. A. Singla, S. Singla, M. Singh, et al. A comparison between modified Alvarado score and RIPASA score in the diagnosis of acute appendicitis Updates Surg, 68 (2016), pp. 351-355.

11. Konan A, Hayran M, Kilic YA, Karakoc D, Kaynaroglu V: Scoring systems in the diagnosis of acute appendicitis in the elderly. Turkish J Trauma Emerg Surg 2011, 17: 396-400. 10.5505/tjtes.2011.03780 
12. Manish Verma, Chanchal, Karamveer, M G Vashist, Kanishk Goyal, Preeti Yadav Comparision of Alvarado And Ripasa Scoring Systems in Diagnosis of Acute Appendicitis Paripex-Indian Journal Of Research, Vol: 4, Issue : 8 August 2015

13. Chong CF, Thien A, Mackie AJ, Tin AS, Tripathi S, Ahmad MA, Tan LT, Ang SH, Telisinghe PU: Comparison of RIPASA and Alvarado scores for the diagnosis of acute appendicitis. Singapore Med J. 2011, 52 (5): 340345.

14. Alnjadat I, Abdallah B. Alvarado verses RIPASA score in diagnosing acute appendicitis. RMJ; 2013; 38(2): 147-51.

15. Erdem H, Centinkunar S, Das K, Reyhan E, Deger C, Aziret M et al. Alvarado, Eskelinen, Ohhmann and Raja Isteri Pengiran Anak Saleha Appendicitis scores for diagnosis of acute appendicitis. World J Gastroenterol; 2013 Dec 21; 19(47): 9057-62 